\title{
Article \\ Effect of Carbonitride Precipitates on the Corrosion Resistance of Low-Alloy Steels under Operating Conditions of Oil-Field Pipelines
}

\author{
Irina Rodionova ${ }^{1}$, Andrey Amezhnov ${ }^{1, * \mathbb{D}}$, Ekaterina Alekseeva ${ }^{2}$, Yuliya Gladchenkova ${ }^{3}$ and Irina Vasechkina ${ }^{4}$ \\ 1 Bardin Central Research Institute of Ferrous Metallurgy, 105005 Moscow, Russia; igrodi@mail.ru \\ 2 Scientific and Technological Complex "New Technologies and Materials", Institute of Advanced Engineering \\ Technologies, Peter the Great St. Petersburg Polytechnic University, 194064 St Petersburg, Russia; \\ alekseeva_el@spbstu.ru \\ 3 Department of Chemistry, Lomonosov Moscow State University, 119991 Moscow, Russia; \\ jubykova@yandex.ru \\ 4 Department of New Materials and Nanotechnologies, National University of Science and Technology MISIS, \\ 119049 Moscow, Russia; i.vasechkina@chermet.net \\ * Correspondence: amejnov@mail.ru; Tel.: +7-903-6872-007
}

\section{check for}

updates

Citation: Rodionova, I.; Amezhnov, A.; Alekseeva, E.; Gladchenkova, Y.; Vasechkina, I. Effect of Carbonitride Precipitates on the Corrosion Resistance of Low-Alloy Steels under Operating Conditions of Oil-Field Pipelines. Metals 2021, 11, 766. https://doi.org/10.3390/met11050766

Academic Editors: Belén

Díaz Fernández and

Andronikos Balaskas

Received: 30 March 2021

Accepted: 4 May 2021

Published: 7 May 2021

Publisher's Note: MDPI stays neutral with regard to jurisdictional claims in published maps and institutional affiliations.

Copyright: (c) 2021 by the authors. Licensee MDPI, Basel, Switzerland. This article is an open access article distributed under the terms and conditions of the Creative Commons Attribution (CC BY) license (https:/ / creativecommons.org/licenses/by/ $4.0 /)$.

\begin{abstract}
An investigation into the corrosion resistance of steels with various contents of carbon and microalloying elements was carried out. It was shown that the presence of a large amount of nanosized (2-3 nm and less) precipitates of the interphase type, particularly niobium carbonitride and vanadium carbonitride, leads to a decrease in the corrosion resistance of hot-rolled sheet products. It was found that, after heat treatment of rolled products at $710^{\circ} \mathrm{C}$, the corrosion resistance of the metal is improved. One of the reasons for this is a decrease in the amount of interphase precipitates, which negatively affect the corrosion resistance of steel, while particles formed in austenite and ferrite do not have such an effect. To ensure high corrosion resistance of steels for oil-field pipelines, microalloying with niobium instead of vanadium is advisable, as well as heat treatment at temperatures above $710{ }^{\circ} \mathrm{C}$.
\end{abstract}

Keywords: low-alloy steels; oil-field pipelines; corrosion resistance; microstructure; chemical composition; nanosized precipitates; excess phases; vanadium carbonitride; niobium carbonitride

\section{Introduction}

The possibilities of increasing the corrosion resistance of carbon and low-alloy steels, operating in neutral aqueous environments, are attracting great attention. The solution to this problem is especially relevant for oil-field pipelines. In addition to crude oil, they transport highly mineralized formation water that intensifies corrosion processes [1,2]. Optimization of the steel chemical composition and microstructure characteristics, as well as an increase in the purity of steel from certain types of non-metallic inclusions, can significantly increase the corrosion resistance of steel and the terms of the trouble-free operation of oil-field pipelines [3].

It was shown that the corrosive activity of complex non-metallic inclusions contained in modern steels depends on their chemical and phase compositions [4]. Their classification is given in $[5,6]$. Herewith, by optimizing the composition of non-metallic inclusions, it is possible to prevent their negative effect on the corrosion resistance of steels under operating conditions of oil-field pipelines. Thus, in the manufacturing of steels with increased corrosion resistance, technological methods that provide a low content and a favorable morphology of the formed non-metallic inclusions are used [7]. However, in addition, the corrosion resistance of steels is influenced by other characteristics of steels, including their chemical composition and microstructure features [8-11]. To identify the influence of these factors, a technique is required for an adequate assessment of the 
corrosion resistance of steels under the considered operating conditions. Electrochemical methods are the most suitable and widespread in this case [12-14].

To increase the adequacy of the assessment of the corrosion rate of carbon and lowalloy steels under the operating conditions of oil-field pipelines with a high $\mathrm{CO}_{2}$ content in the transported medium, a new technique was developed [11,15]. It is widely used at the present time, including in this work, and has the following name: "Method for determining the corrosion resistance of carbon and low-alloy steels and products made of them by measuring the saturation current density of the anodic dissolution of steel in corrosive environment by electrochemical method". The test results, according to the developed method, correlate well with the real corrosion rate under the above-mentioned operating conditions. At a saturation current density of less than $6.2 \mathrm{~mA} / \mathrm{cm}^{2}$, the corrosion rate under operating conditions is no more than $0.3 \mathrm{~mm} /$ year. An increase in the saturation current density to $8.5 \mathrm{~mA} / \mathrm{cm}^{2}$ corresponds to an increase in the corrosion rate to $2.2 \mathrm{~mm} /$ year. This technique is conventionally called the current density measurement (CDM) method.

Using the CDM method in [9-11], the effect of the chemical composition and structural characteristics on the corrosion resistance of steels in aqueous environments was investigated. It was shown in [10] that high-strength rolled products with the structure of acicular ferrite and martensitic-austenitic regions have a lower corrosion resistance than steels with a ferrite-pearlite structure of lower strength classes. A significant decrease in the corrosion resistance of the investigated steels occurs with an increase in the size of martensite islands, which have a lath morphology. Heat treatment of ferrite-pearlite steels, which contain a sufficient number of microalloying elements, leads to an increase in both strength and corrosion resistance. This occurs if rolling is carried out according to regimes that prevent the formation of martensitic regions in the structure. Notably, accelerated cooling should be completed at higher temperatures, and then the sheets should be tempered. This will promote the formation of nanosized precipitates of optimal morphology, which do not reduce corrosion resistance, but provide the required level of strength due to precipitation hardening.

It was shown that, to ensure the high corrosion resistance of steels under the operating conditions of oil-field pipelines, it is advisable to alloy the steels with chromium and copper [9]. The results of [9] demonstrate that the formation of an excess amount of nanosized precipitates of niobium carbonitrides (carbides) and a decrease in their size, especially to 1-2 nm and less, can lead to a decrease in corrosion resistance. Later, in [11], it was found that the presence of a large amount of nanosized (2-3 nm and less) precipitates of interphase type $[16,17]$ in steel leads to a decrease in the corrosion resistance of hot-rolled sheet products. This was observed in the case of niobium carbonitride and especially vanadium carbonitride. A characteristic feature of these particles is that they precipitate during the polymorphic transformation along the planes, corresponding to the positions of the $\gamma-\alpha$ transformation front [18]. It was shown that the corrosion resistance of hot rolled low carbon (not more than $0.085 \mathrm{wt} . \% \mathrm{C}$ ) steel microalloyed with $\mathrm{V}$ and /or $\mathrm{Nb}$ decreases with an increase in the content of carbon and microalloying elements [11]. This could be due to the formation of nanosized carbonitride precipitates. The negative effect of these precipitates on corrosion resistance was confirmed by the results presented in [19]. It was also found that, after heat treatment of rolled products at $700-720^{\circ} \mathrm{C}$ and higher, the corrosion resistance of steel, which contains nanosized carbonitride precipitates, improves. The authors suggested that one of the reasons for this was an increase in the fraction of precipitates formed in ferrite, which, in contrast to interphase precipitates, do not have a negative effect on the corrosion resistance of steel.

The lack of scientific publications devoted to the study of the effect of excess phases on the resistance of low-alloy steels to corrosion, proceeding according to the classical electrochemical mechanism, which is typical for oil-field conditions, should be noted. There are several investigations of the influence of precipitations with microalloying elements on the susceptibility of hydrogen embrittlement. Thus, studies [20-24] have shown a favorable effect of microalloying with $\mathrm{Ti}, \mathrm{Nb}$, and $\mathrm{V}$ on the resistance to hydrogen-induced damage 
of boron-containing steels for hot stamping due to the presence of dispersed precipitates of carbides, which act as irreversible traps of hydrogen. At the same time, the presence of such precipitates can have a negative effect on the resistance to electrochemical corrosion. The effect of these microalloying elements on the mechanical properties and microstructure of steel has been well studied [25-29].

However, the influence of nanosized precipitates of excess phases on the resistance of steel to electrochemical corrosion has not been investigated. Thus, the aim of this work was to study the effect of the chemical composition (content of carbon and microalloying elements), as well as the parameters of the microstructure, including the characteristics of nanosized precipitates of excess phases, on the corrosion resistance of steels under the operating conditions of oil-field pipelines.

\section{Materials and Methods}

The study was carried out using samples of laboratory-made steel sheet products. Steels were smelted in "Vacuum Industries" induction furnace in a nitrogen atmosphere. Steels were poured into a mold in a furnace chamber. The weight of the ingots was $9 \mathrm{~kg}$. After forging the ingots, the billets had dimensions of $50 \times 100 \times 60 \mathrm{~mm}$ with a maximum deviation of $\pm 5 \mathrm{~mm}$. Then, the billets were rolled into strips with a thickness of $5 \mathrm{~mm}$ using laboratory DUO 300 mill (VNIIMETMASH Holding Company, Moscow, Russia). The reduction in the last two passes was $15-25 \%$. The rolling start temperature was $1180{ }^{\circ} \mathrm{C}$, and the rolling end temperature was $860^{\circ} \mathrm{C}$. After rolling, the strips were rapidly cooled to a temperature of $600^{\circ} \mathrm{C}$; then, they were placed in a batch furnace (VNIIMETMASH Holding Company, Moscow, Russia)heated to a temperature of $600{ }^{\circ} \mathrm{C}$ and cooled with the furnace to room temperature (imitation of coiled coil cooling). The temperature was measured before and after each pass using a handheld "Thermoscope-100" IR-pyrometer (INFRATEST, Moscow, Russia). A caliper was used to measure the final strip thickness.

The steels under the study differed in the content of the microalloying elements niobium or vanadium, as well as carbon (Table 1). The chemical composition of the samples of the investigated steels was determined by the method of emission spectral analysis using "Spectro Lab" emission spectrometer (Spectro Analytical Instruments GmbH, Kleve, Germany). The range of measured concentrations of elements is from 0.000 to $99.9 \%$; the optical wavelength range, $\mathrm{nm}-180-800$; relative measurement error- $10 \%$.

Table 1. Chemical composition of the investigated steels, wt. $\%$.

\begin{tabular}{ccccccccccccc}
\hline Steel, No & $\mathbf{C}$ & $\mathbf{S i}$ & $\mathbf{M n}$ & $\mathbf{P}$ & $\mathbf{S}$ & $\mathbf{C r}$ & $\mathbf{N i}$ & $\mathbf{C u}$ & $\mathbf{A l}$ & $\mathbf{N}$ & $\mathbf{V}$ & $\mathbf{N b}$ \\
\hline 1 & 0.040 & 0.23 & 0.65 & 0.006 & 0.002 & 0.42 & 0.08 & 0.14 & 0.031 & 0.009 & 0.004 & 0.029 \\
2 & 0.058 & 0.19 & 0.72 & 0.005 & 0.002 & 0.46 & 0.09 & 0.14 & 0.026 & 0.011 & 0.003 & 0.028 \\
3 & 0.082 & 0.21 & 0.63 & 0.007 & 0.002 & 0.45 & 0.07 & 0.13 & 0.035 & 0.009 & 0.003 & 0.030 \\
4 & 0.039 & 0.20 & 0.62 & 0.006 & 0.002 & 0.44 & 0.08 & 0.12 & 0.029 & 0.010 & 0.003 & 0.041 \\
5 & 0.060 & 0.19 & 0.68 & 0.007 & 0.002 & 0.45 & 0.08 & 0.13 & 0.031 & 0.009 & 0.003 & 0.040 \\
6 & 0.081 & 0.21 & 0.67 & 0.007 & 0.002 & 0.45 & 0.07 & 0.13 & 0.028 & 0.011 & 0.004 & 0.039 \\
7 & 0.038 & 0.22 & 0.69 & 0.006 & 0.002 & 0.46 & 0.09 & 0.16 & 0.024 & 0.010 & 0.003 & 0.050 \\
8 & 0.061 & 0.21 & 0.71 & 0.006 & 0.002 & 0.44 & 0.10 & 0.14 & 0.035 & 0.012 & 0.003 & 0.052 \\
9 & 0.079 & 0.23 & 0.70 & 0.007 & 0.002 & 0.43 & 0.11 & 0.16 & 0.030 & 0.011 & 0.004 & 0.051 \\
10 & 0.042 & 0.24 & 0.69 & 0.007 & 0.002 & 0.46 & 0.11 & 0.14 & 0.030 & 0.010 & 0.042 & 0.002 \\
11 & 0.060 & 0.22 & 0.65 & 0.006 & 0.002 & 0.43 & 0.09 & 0.13 & 0.029 & 0.012 & 0.043 & 0.002 \\
12 & 0.078 & 0.24 & 0.66 & 0.005 & 0.002 & 0.42 & 0.10 & 0.12 & 0.031 & 0.009 & 0.042 & 0.002 \\
13 & 0.039 & 0.24 & 0.66 & 0.006 & 0.002 & 0.44 & 0.09 & 0.14 & 0.030 & 0.012 & 0.061 & 0.002 \\
14 & 0.061 & 0.25 & 0.67 & 0.006 & 0.002 & 0.45 & 0.11 & 0.13 & 0.028 & 0.011 & 0.060 & 0.002 \\
15 & 0.079 & 0.23 & 0.68 & 0.006 & 0.002 & 0.45 & 0.12 & 0.13 & 0.030 & 0.011 & 0.060 & 0.002 \\
16 & 0.040 & 0.22 & 0.68 & 0.006 & 0.002 & 0.43 & 0.09 & 0.15 & 0.032 & 0.012 & 0.075 & 0.002 \\
17 & 0.059 & 0.23 & 0.69 & 0.007 & 0.002 & 0.44 & 0.10 & 0.14 & 0.031 & 0.011 & 0.077 & 0.002 \\
18 & 0.081 & 0.22 & 0.68 & 0.006 & 0.002 & 0.45 & 0.11 & 0.13 & 0.029 & 0.010 & 0.078 & 0.002 \\
\hline
\end{tabular}


To establish the effect of niobium and vanadium, two groups of steels were smelted: $\mathrm{Nb}$-microalloyed (No 1-9) and V-microalloyed (No 10-18). In order to determine the optimal concentration of each of the microalloying elements (niobium and vanadium), which does not lead to a decrease in the corrosion resistance of steels, their content was varied at three levels. In the first group, the niobium concentration was (wt. $\%): \approx 0.03$ (No 1-3), $\approx 0.04$ (No 4-6), and $\approx 0.05$ (No 7-9). Similarly, for steels microalloyed with vanadium, the content varied at three levels (wt.\%): 0.04 (No 10-12), 0.06 (No 13-15), and 0.08 (No 16-18). Due to the fact that the carbon content in modern pipe steels can differ, while carbon can bind niobium and vanadium into carbides, for each level of niobium and vanadium content, the carbon content was varied at three levels (wt. \%): 0.04, 0.06, and 0.08. The concentration of other elements for all steels varied within narrow limits and on average was (wt.\%): $\mathrm{Si}-0.22, \mathrm{Mn}-0.67, \mathrm{Cr}-0.44, \mathrm{Ni}-0.09, \mathrm{Cu}-0.14, \mathrm{Al}-0.03$, $\mathrm{N}-0.011$. The content of impurities was low and amounted to $0.002 \mathrm{wt} . \%$ sulfur and about $0.006 \mathrm{wt} . \%$ phosphorus. The chosen wider range of variation of the vanadium concentration in comparison with niobium (0.04-0.08 wt.\% instead of $0.03-0.05 \mathrm{wt} . \%)$ is explained by its correspondence to many steels currently used for oil-field pipelines.

The microstructure of the samples was assessed using "Neofot" optical microscope (Carl Zeiss, Oberkochen, Germany). All steels had a ferrite-pearlite structure with a small pearlite content, which corresponds to the relatively low carbon content in the studied steels. For each steel, the secant method was used to determine the ferrite grain size in two directions: along the rolling direction and across the rolling direction, respectively, $D_{x}$ and $D_{y}$, the average grain size in two directions $D_{a v}$, as well as the coefficient of grain elongation $D_{\mathrm{x}} / \mathrm{D}_{\mathrm{y}}$.

The corrosion resistance of the investigated steels was determined according to the CDM method mentioned above, immediately after hot rolling, as well as after heat treatment at 670 and at $710^{\circ} \mathrm{C}$ (heating and holding time was $20 \mathrm{~min}$ ). Figure 1 shows a view of an electrochemical cell, and Figure 2 shows a view of a sample before and after testing.

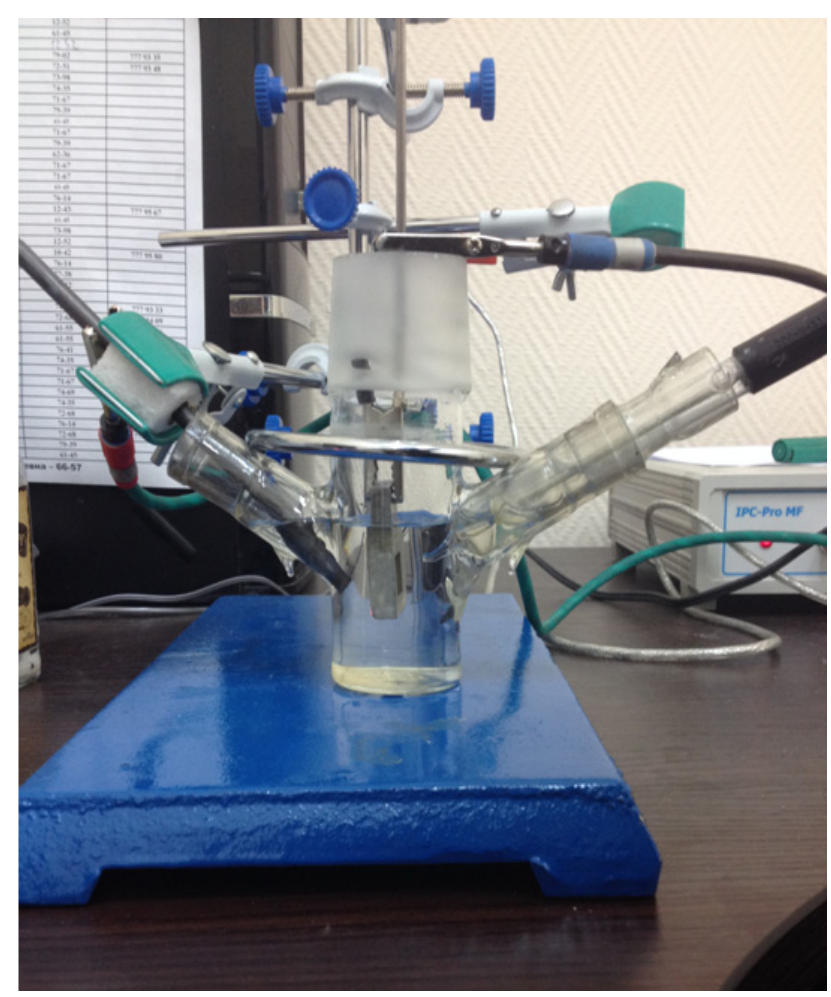

Figure 1. View of the electrochemical cell. 


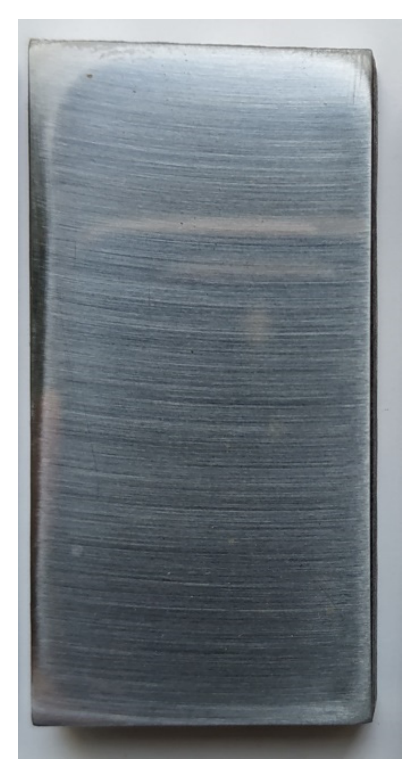

(a)

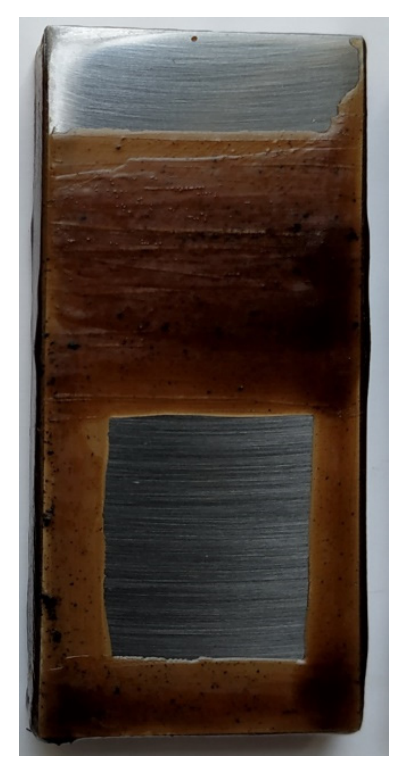

(b)

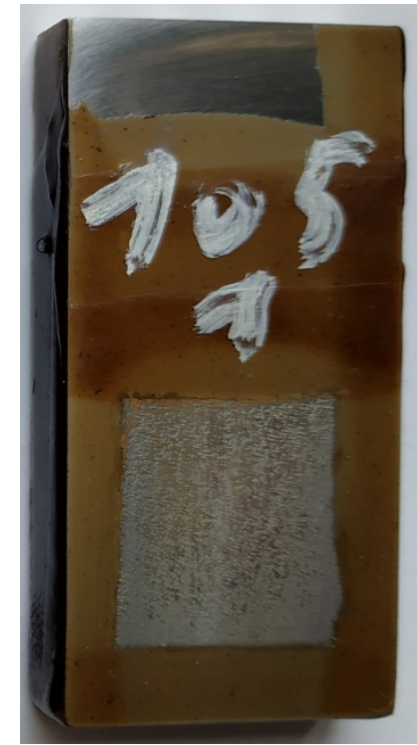

(c)

Figure 2. Type of samples for electrochemical tests: (a) Before testing and paraffin coating; (b) Before testing after paraffin coating; (c) After testing.

The criterion for corrosion resistance is the value of the saturation current density established on the sample after holding it in a model environment at a potential of $\mathrm{E}=-300 \mathrm{mV}$ (relative to a saturated silver chloride reference electrode) for $1 \mathrm{~h}$. It is important to note that this technique was developed specifically to assess the corrosion resistance of steels for oil-field pipelines. Its creation was needed as none of the standardized, including electrochemical, methods for assessing corrosion resistance provided results that correlate with the real corrosion rate of steels under operating conditions.

Additional studies of the microstructure, including the characteristics of nanosized precipitates of excess phases, were carried out by transmission electron microscopy of foils using "JEM 200CX" ("JEOL", Akishima, Japan) electron microscope at an accelerating voltage of $120 \mathrm{kV}$. Special attention was paid to analyzing the nanosized particles of carbonitrides (carbides) of microalloying elements. They were conventionally divided into four types, depending on the technological cycle in which they were formed and the phase composition of the metal matrix:

1 -precipitates formed in austenite (austenitic), 2-precipitates formed during $\gamma \rightarrow$ $\alpha$ transformation (interphase), 3-precipitates formed during $\gamma \rightarrow \alpha$ transformation, but grown in ferrite after the end of the transformation (mixed type), 4 -precipitates formed in ferrite (ferritic). The identifying characteristics of each type are presented in [12-14]. The systematization of these features is described below.

\section{Results and Discussion}

Laboratory smelting of investigated steels was carried out using deoxidation with aluminum. Therefore, corundum inclusions were the main products of deoxidation. That is, complex non-metallic inclusions with an oxide component of a complex composition, which are present in modern steels of industrial smelting, were absent in the steels under study. The close content of aluminum in them indicates that the contamination of these steels with traditional non-metallic inclusions, including corundum, is close. Thus, the results presented below make it possible to assess the dependence of corrosion resistance of steels on, namely, the characteristics of precipitates of excess phases formed with the participation of microalloying elements: carbides or carbonitrides.

Table 2 shows the results of metallographic studies of the grain structure characteristics, as well as indicators of the corrosion resistance of the investigated steels determined by the CDM method: the values of the saturation current density $\left(i_{\mathrm{s}}\right)$ after hot rolling and heat 
treatment at temperatures of 670 and $710^{\circ} \mathrm{C}$. For each steel and each condition (hot-rolled$\mathrm{h} / \mathrm{r}$, heat-treated at $670{ }^{\circ} \mathrm{C}-\mathrm{T} 670{ }^{\circ} \mathrm{C}$, heat-treated at $710^{\circ} \mathrm{C}-\mathrm{T} 710^{\circ} \mathrm{C}$ ), three samples were tested.

Table 2. Grain structure characteristics and indicators of corrosion resistance of the investigated steels.

\begin{tabular}{|c|c|c|c|c|c|c|c|}
\hline \multirow{2}{*}{ Steel, No } & \multirow{2}{*}{$D_{x}, \mu m$} & \multirow{2}{*}{$\mathrm{D}_{\mathrm{y}}, \mu \mathrm{m}$} & \multirow{2}{*}{$D_{x} / D_{y}$} & \multirow{2}{*}{$\mathrm{D}_{\mathrm{m}}, \mu \mathrm{m}$} & \multicolumn{3}{|c|}{$i_{\mathrm{s},} \mathrm{mA} / \mathrm{cm}^{2}$} \\
\hline & & & & & $h / r$ & $\mathrm{~T} 670{ }^{\circ} \mathrm{C}$ & $\mathrm{T} 710^{\circ} \mathrm{C}$ \\
\hline 1 & 6.5 & 4.2 & 1.55 & 5.4 & $5.27 \pm 0.07$ & $5.23 \pm 0.09$ & $5.25 \pm 0.11$ \\
\hline 2 & 6.4 & 4.0 & 1.60 & 5.2 & $5.31 \pm 0.10$ & $5.33 \pm 0.07$ & $5.29 \pm 0.15$ \\
\hline 3 & 6.2 & 3.8 & 1.63 & 5.0 & $5.33 \pm 0.07$ & $5.37 \pm 0.09$ & $5.31 \pm 0.08$ \\
\hline 4 & 6.3 & 4.0 & 1.58 & 5.2 & $5.37 \pm 0.08$ & $5.35 \pm 0.09$ & $5.33 \pm 0.07$ \\
\hline 5 & 6.1 & 3.8 & 1.61 & 5.0 & $5.48 \pm 0.07$ & $5.45 \pm 0.07$ & $5.33 \pm 0.09$ \\
\hline 6 & 5.8 & 3.5 & 1.66 & 4.7 & $5.85 \pm 0.09$ & $5.79 \pm 0.05$ & $5.48 \pm 0.06$ \\
\hline 7 & 6.0 & 3.4 & 1.76 & 4.7 & $5.90 \pm 0.05$ & $5.83 \pm 0.08$ & $5.61 \pm 0.10$ \\
\hline 8 & 5.9 & 3.3 & 1.79 & 4.6 & $6.35 \pm 0.14$ & $6.25 \pm 0.12$ & $5.75 \pm 0.10$ \\
\hline 9 & 5.7 & 3.1 & 1.84 & 4.4 & $6.53 \pm 0.08$ & $6.38 \pm 0.11$ & $5.95 \pm 0.12$ \\
\hline 10 & 6.8 & 4.7 & 1.45 & 5.7 & $5.25 \pm 0.09$ & $5.21 \pm 0.07$ & $5.15 \pm 0.09$ \\
\hline 11 & 6.6 & 4.5 & 1.47 & 5.6 & $5.32 \pm 0.10$ & $5.28 \pm 0.10$ & $5.27 \pm 0.08$ \\
\hline 12 & 6.4 & 4.3 & 1.49 & 5.4 & $5.38 \pm 0.06$ & $5.35 \pm 0.06$ & $5.32 \pm 0.09$ \\
\hline 13 & 6.7 & 4.5 & 1.49 & 5.6 & $5.45 \pm 0.07$ & $5.42 \pm 0.09$ & $5.38 \pm 0.07$ \\
\hline 14 & 6.5 & 4.3 & 1.51 & 5.4 & $5.81 \pm 0.09$ & $5.79 \pm 0.09$ & $5.48 \pm 0.11$ \\
\hline 15 & 6.3 & 4.1 & 1.54 & 5.2 & $6.19 \pm 0.11$ & $6.15 \pm 0.11$ & $5.73 \pm 0.08$ \\
\hline 16 & 6.5 & 4.3 & 1.51 & 5.4 & $6.22 \pm 0.10$ & $6.17 \pm 0.13$ & $6.05 \pm 0.10$ \\
\hline 17 & 6.2 & 4.0 & 1.55 & 5.1 & $6.53 \pm 0.09$ & $6.50 \pm 0.10$ & $6.12 \pm 0.08$ \\
\hline 18 & 6.0 & 3.8 & 1.58 & 4.9 & $6.79 \pm 0.15$ & $6.65 \pm 0.10$ & $6.22 \pm 0.12$ \\
\hline
\end{tabular}

In $\mathrm{Nb}$-microalloyed steels, slightly finer grains are obtained than in V-microalloyed steels, especially in the direction perpendicular to the direction of rolling. The large elongation of the grains is also associated with this. Within each of the studied groups of steels, a decrease in grain size is observed with an increase in the content of microalloying elements and carbon. Figure 3 shows a typical view of the microstructure of the investigated steels of some variants.

For $\mathrm{Nb}$-microalloyed steels with $0.028-0.03 \mathrm{wt} . \% \mathrm{Nb}$, a high corrosion resistance is obtained regardless of the carbon content-the values of $i_{\mathrm{s}}$ are from 5.23 to $5.37 \mathrm{~mA} / \mathrm{cm}^{2}$ (Figure 4). With an increase in the niobium content to $0.04 \mathrm{wt}$.\% for steels with medium and high carbon content, a decrease in the corrosion resistance of rolled products, both hotrolled and after heat treatment at $670{ }^{\circ} \mathrm{C}$, is observed-the values of $i_{\mathrm{s}}$ are $5.45-5.85 \mathrm{~mA} / \mathrm{cm}^{2}$. Heat treatment at $710^{\circ} \mathrm{C}$ leads to an improvement in the corrosion resistance of the rolled products-the values of $i_{\mathrm{s}}$ become below $5.5 \mathrm{~mA} / \mathrm{cm}^{2}$. A further increase in the niobium content to $0.05 \mathrm{wt}$ \% leads to an even greater decrease in corrosion resistance, especially for steels with medium and high carbon content-the values of $i_{\mathrm{S}}$ after hot rolling and after heat treatment at $670{ }^{\circ} \mathrm{C}$ rise to $6.25-6.53 \mathrm{~mA} / \mathrm{cm}^{2}$. As a result of heat treatment at $710{ }^{\circ} \mathrm{C}$, the corrosion resistance of the rolled products is improved-the values of $i_{\mathrm{s}}$ become lower than $6.0 \mathrm{~mA} / \mathrm{cm}^{2}$.

For V-microalloyed steels with $\sim 0.04 \mathrm{wt} . \% \mathrm{~V}$ a high corrosion resistance is obtained regardless of the carbon content-the values of $i_{\mathrm{s}}$ range from 5.15 to $5.38 \mathrm{~mA} / \mathrm{cm}^{2}$, that is, in fact, at the same level as for $\mathrm{Nb}$-microalloyed steel with $\mathrm{Nb}$ content of about $0.03 \mathrm{wt} . \%$ (Table 2 and Figure 5). An increase in the vanadium content to $0.06 \mathrm{wt}$. $\%$ leads to a slight decrease in the corrosion resistance of steel with a medium and high carbon content-the values of $i_{\mathrm{s}}$ after hot rolling and heat treatment at $670{ }^{\circ} \mathrm{C}$ are $5.79-6.19 \mathrm{~mA} / \mathrm{cm}^{2}$. Heat treatment at $710{ }^{\circ} \mathrm{C}$ leads to an improvement in the corrosion resistance of the rolled products - the values of $i_{\mathrm{s}}$ are below $5.8 \mathrm{~mA} / \mathrm{cm}^{2}$. A further increase in the vanadium content to $0.08 \mathrm{wt}$ \% leads to an even greater decrease in corrosion resistance, especially for steels with medium and high carbon content - the values of $i_{\mathrm{s}}$ after hot rolling and after heat treatment at $670{ }^{\circ} \mathrm{C}$ rise to $6.50-6.79 \mathrm{~mA} / \mathrm{cm}^{2}$. Heat treatment at $710^{\circ} \mathrm{C}$ results in a 
significant improvement in the corrosion resistance of the rolled products-the values of $i_{\mathrm{s}}$ are below $6.3 \mathrm{~mA} / \mathrm{cm}^{2}$.

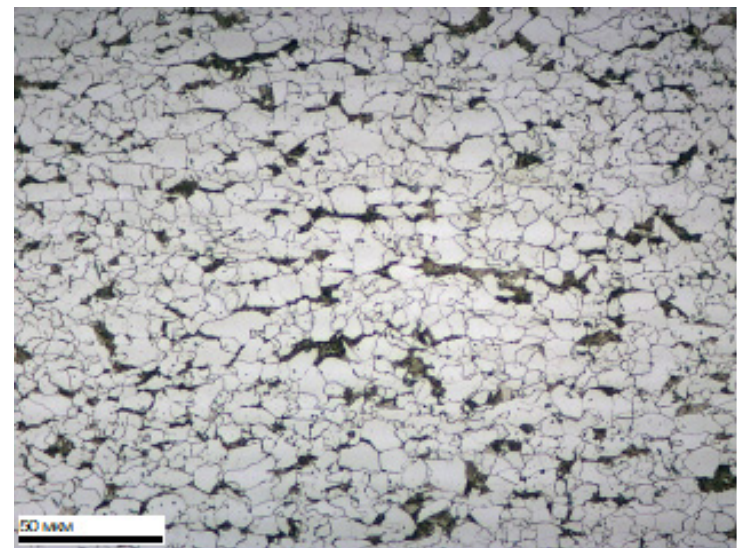

(a)

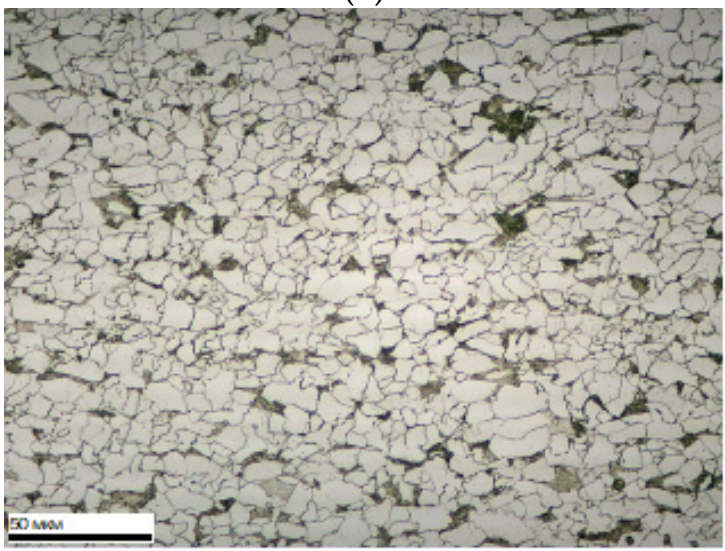

(c)

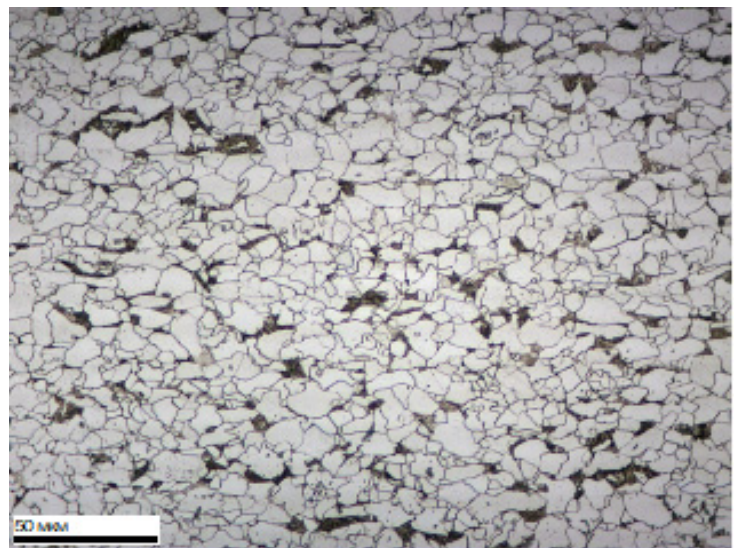

(b)

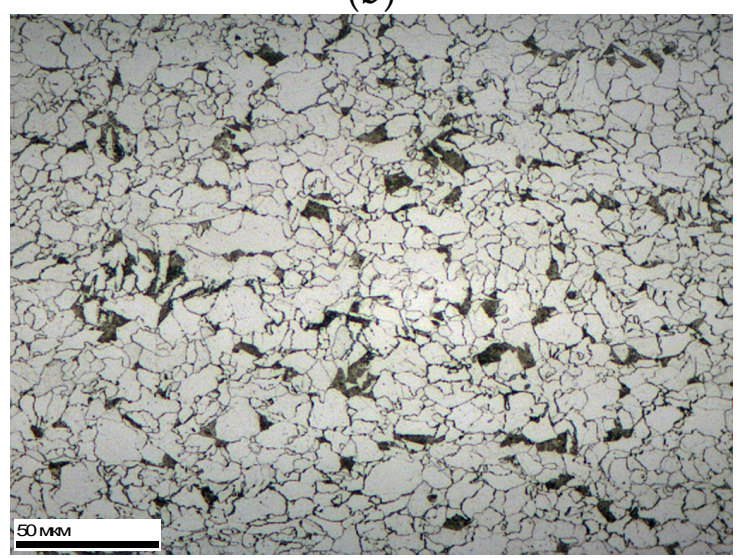

(d)

Figure 3. Microstructure of steels: (a) Steel No 2; (b) Steel No. 5; (c) Steel No. 14; (d) Steel No. 17.

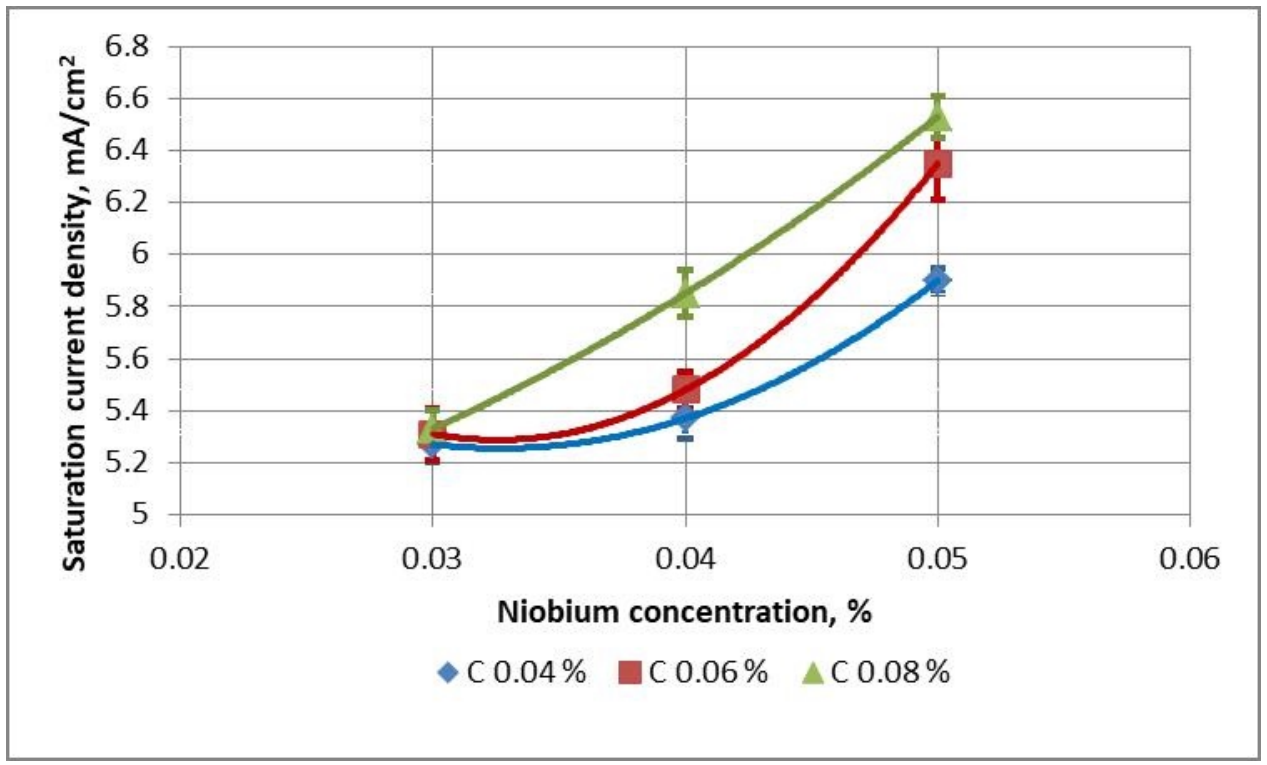

Figure 4. Dependence of the saturation current density on the niobium content at various carbon content. 


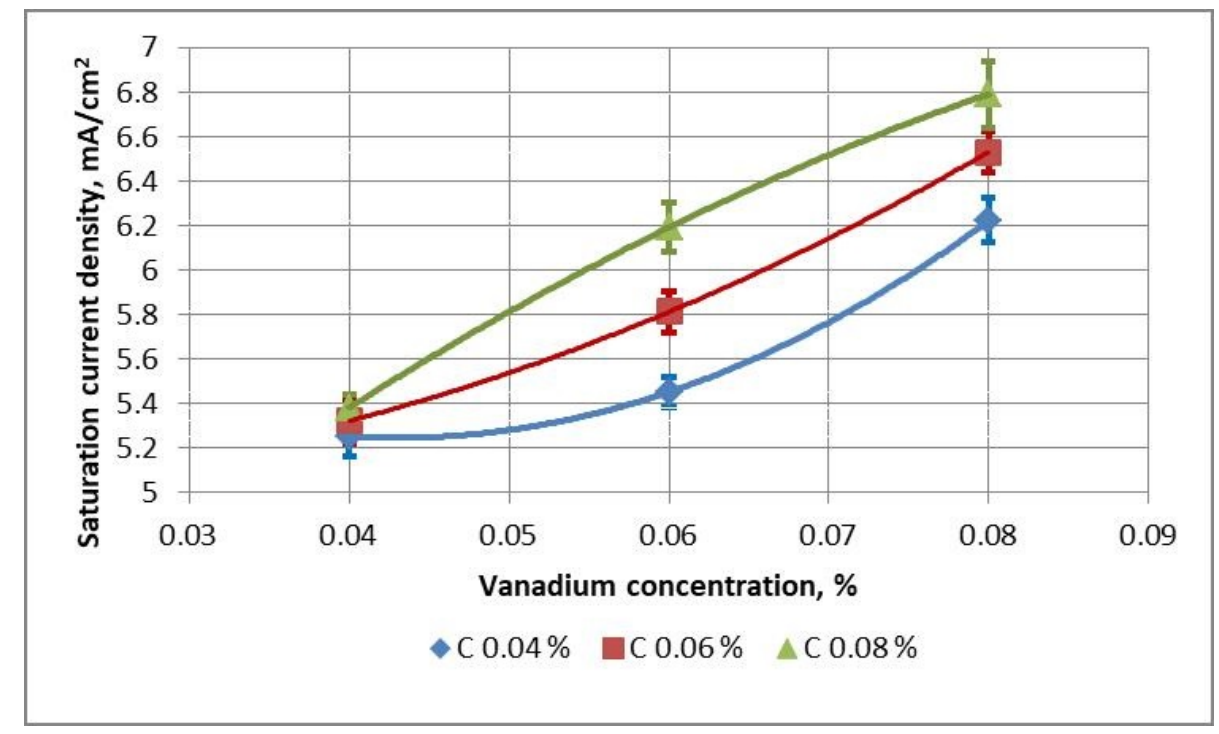

Figure 5. Dependence of the saturation current density on the vanadium content at various carbon content.

On average, the level of corrosion resistance of steels microalloyed with vanadium is slightly lower than that of steels microalloyed with niobium. This is, in part, consistent with the results of previous studies. It was previously shown that, for steels microalloyed with vanadium, a slight decrease in corrosion resistance is observed due to the formation of a certain type of precipitation of excess phases [11]. The close values of the characteristics of the grain structure make them unlikely to affect the corrosion resistance indicators. Taking the above literature data into account $[9,11,19]$ it can be assumed that the main influence on the corrosion resistance indicators is exerted by the characteristics of nanosized precipitates of carbonitride (carbide) excess phases. To understand the mechanisms of the revealed effect of the chemical composition on the corrosion resistance, the study of carbonitride (carbide) precipitates in investigated rolled steels that showed different corrosion resistance was carried out using a transmission electron microscope. Initially, samples of steels with a lower content of niobium and vanadium, respectively, 0.03 and $0.04 \mathrm{wt} . \%$, which showed the highest corrosion resistance, both after hot rolling and after heat treatment, were investigated. Nanosized carbonitrides in most areas of the studied samples are either not detected at all or are detected in no more than 2-3 precipitates in the image field $\sim 2.8-2.2 \mu \mathrm{m}$ (Figure 6a). In addition to precipitates in the bodies of grains/blocks, nanosized carbonitrides are sometimes found along their boundaries (Figure 6b), also in low numbers.

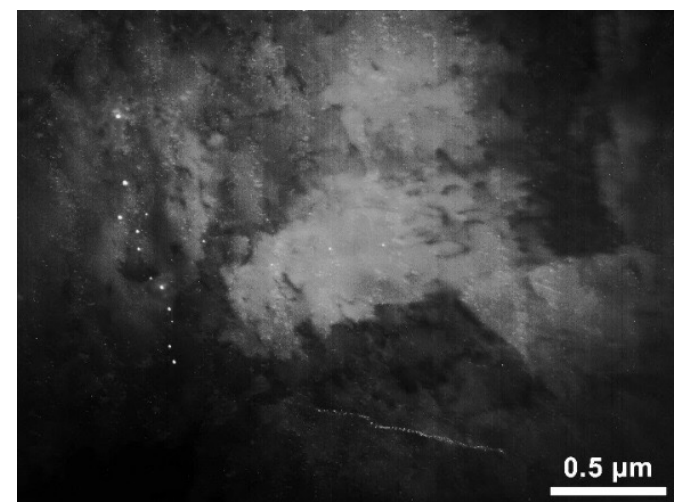

(a)

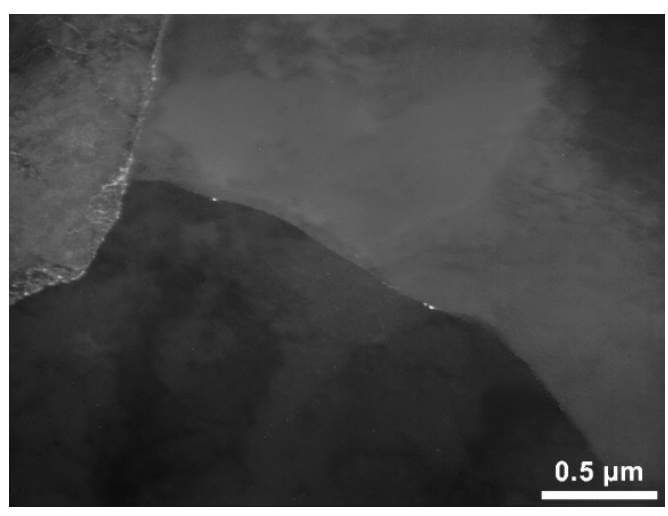

(b)

Figure 6. Dark-field image in the reflections of nanosized carbonitrides (steel No 2): (a) In the grain body; (b) Along the grain boundaries. 
The characteristic size of precipitates is about $4-15 \mathrm{~nm}$ in length (up to $15 \mathrm{~nm}$ ). The shape of the precipitates is elongated to a different extent; sometimes the particles are narrow. The type of these precipitates is austenitic. The arrangement of austenitic precipitates may be various: in some cases, it is uniform (chaotic), in others, the precipitates form multidirectional dense chains that close and intersect, and there are usually few particles outside the chains in this variant. The length of the chains may be large, up to 5-10 microns. Reflexes in the microdiffraction pattern (MDP), as a rule, have tangential blurring (it means the disorientation of particles), sometimes quite significant (several degrees). No interphase precipitates were found. Taking the results of earlier studies into account [11,15], it can be concluded that the main reason for the high corrosion resistance of such steels is a small amount of nanosized precipitates, in the complete absence of particles of the interphase type. This is one of the new scientific results obtained in the framework of this study. The obtained results indicate that, in steels containing no more than $0.03 \%$ niobium and no more than $0.04 \%$ vanadium, interphase particles are not formed, and high corrosion resistance is provided without additional thermal processing. In the hot-rolled sample with an average niobium content of $0.04 \mathrm{wt} . \%$, two types of precipitates were revealed-formed in austenite (Figure 7a,b) and interphase (Figure 7c,d).

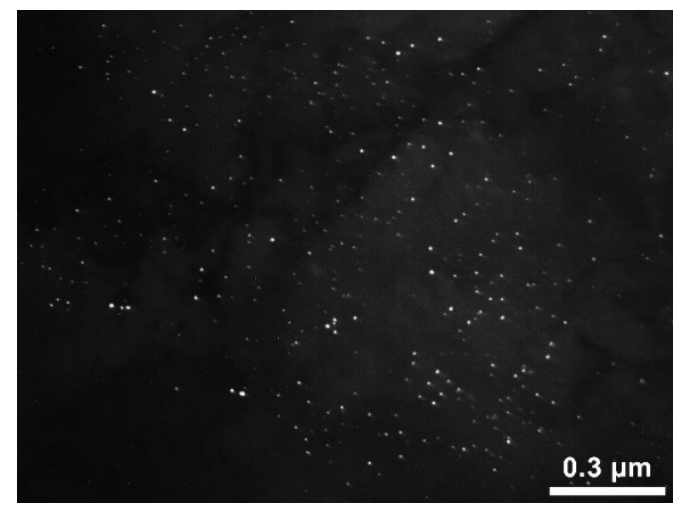

(a)

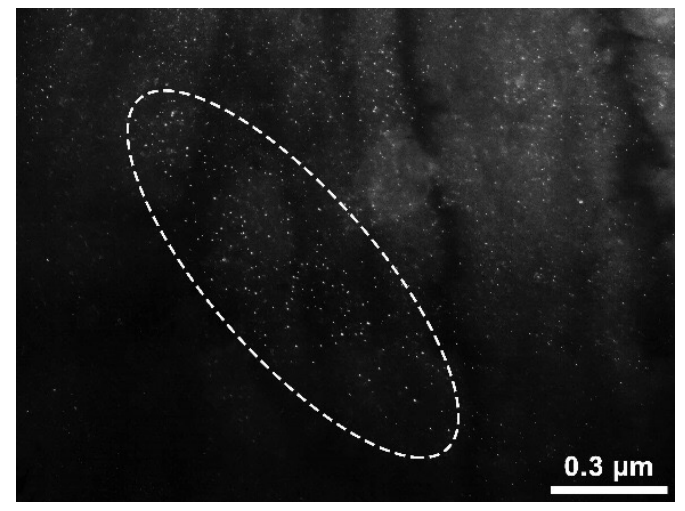

(c)

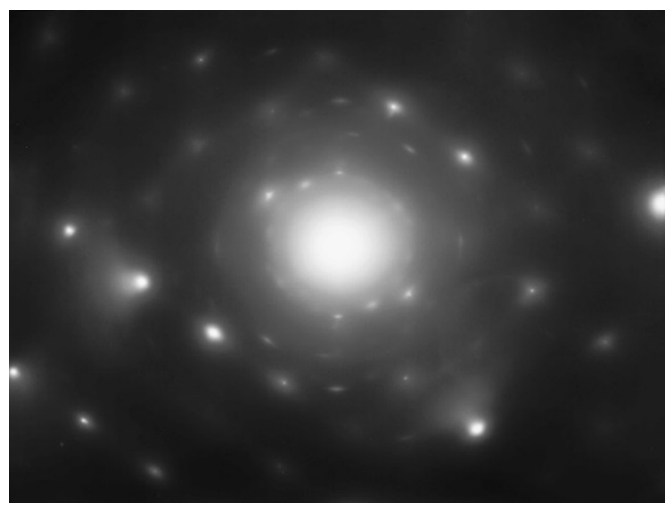

(b)

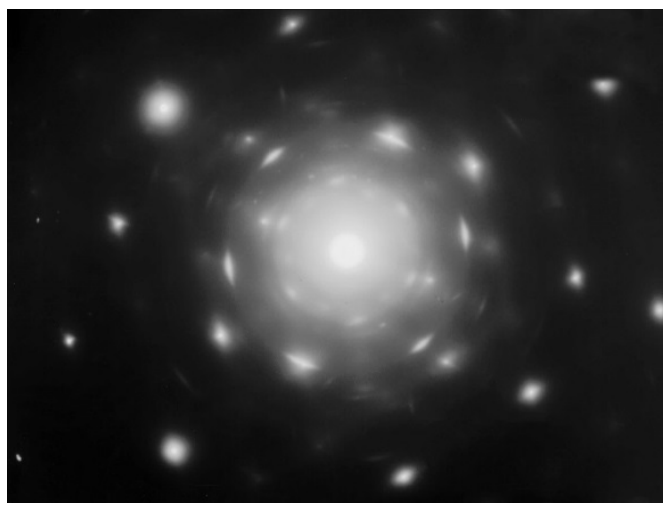

(d)

Figure 7. Dark-field image in reflections of nanosized carbonitrides (steel No 5): (a) Formed in austenite (advantage in the dedicated area); (c) Interphase; (b,d) Diffraction patterns to them.

There are also submicron precipitates (Figure 8), their size is about 60-120 nm. Some of these are indicated by arrows in the figure. The shape of the largest precipitates is dendritic, of the relatively small, closer to equiaxial (strongly rounded dendrites). 


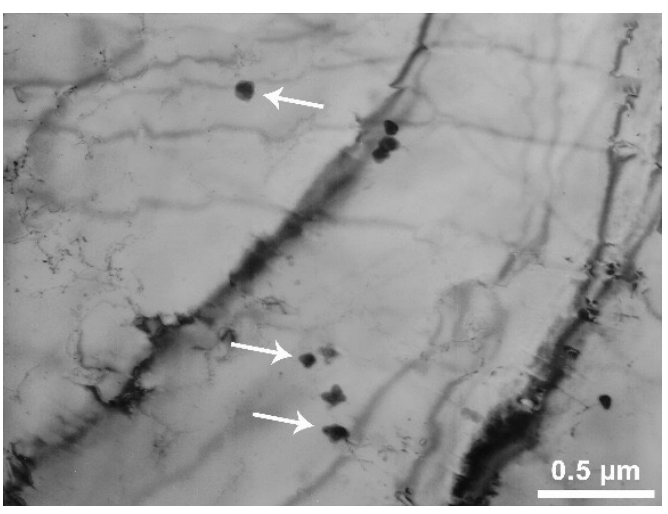

(a)

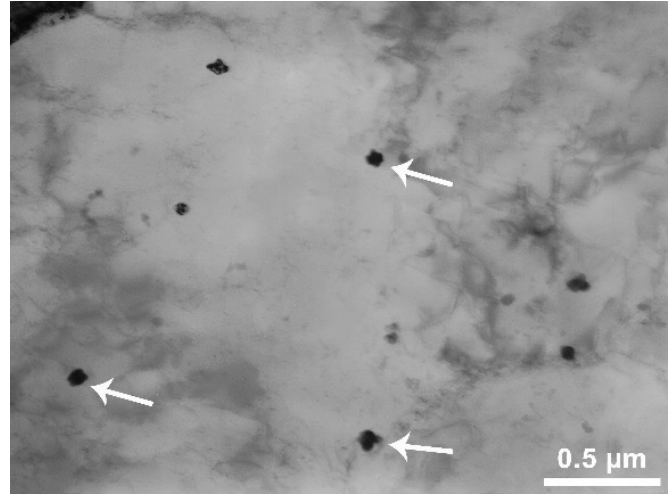

(b)

Figure 8. Brightfield image: view of submicron precipitates in steel No 5 (arrows indicate some precipitates): (a) Shape precipitates is dendritic; (b) Closer to equiaxial.

The sizes of interphase precipitates are no more than $3-5 \mathrm{~nm}$; a significant fraction of precipitates (probably large) have a size of less than $2 \mathrm{~nm}$. Such precipitates are poorly detected in electron microscopic images. The effects associated with the presence of the precipitates are almost invisible in microdiffraction patterns because of the blurring of reflections due to the small size of the precipitates. In a hot-rolled specimen with an average vanadium content of $0.06 \%$ with medium carbon content (steel No 14), in one case, an arrangement characteristic for precipitates of the interphase type was observed, in the form of approximately parallel chains [16-18] (Figure 9a). In addition to interphase precipitates, in some places, carbide particles formed in ferrite were found (Figure 9b). The characteristic arrangement of ferritic precipitates is in the form of a set of individual precipitates and short (usually within 1-2 microns), not quite straight chains, directed relative to each other at an oblique angle. Reflexes from precipitates on the MDP have the form of long radial bands, which is explained by the peculiarities of the internal structure of particles (the presence of a large number of plane-stacking faults).

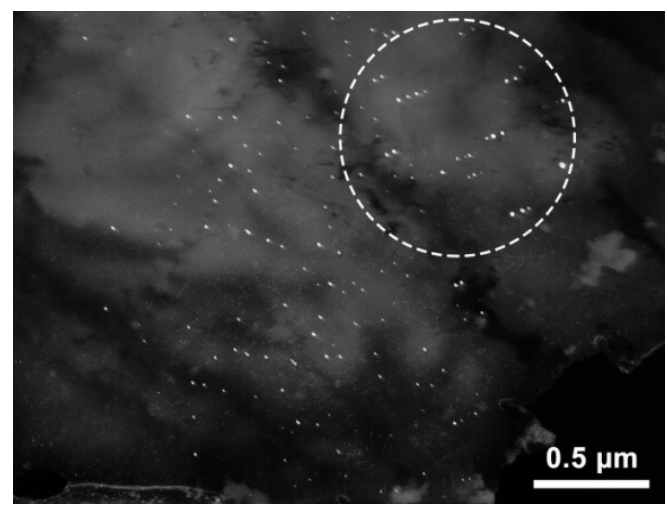

(a)

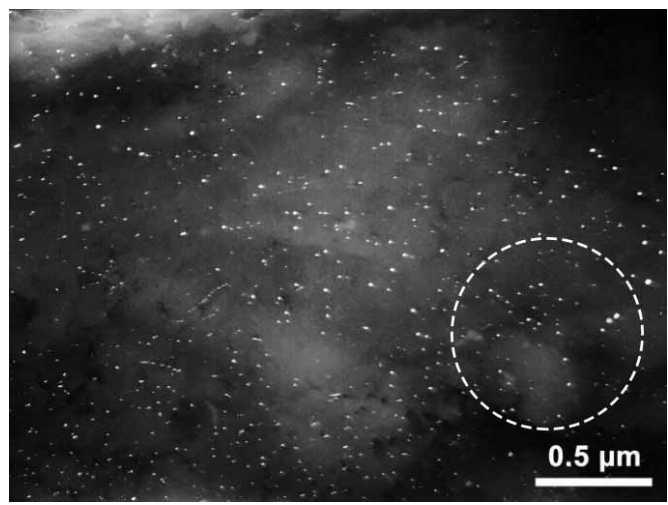

(b)

Figure 9. Dark-field image in the reflections of nanosized carbonitrides (steel No 14): (a) Area with precipitates of interphase type (circled); (b) Areas with precipitates formed in ferrite (circled).

The volume density of these precipitates is very low in all cases; therefore, there are no effects on the MDP associated with their presence. The precipitates were identified as being formed in ferrite because of their characteristic mutual arrangement in the form of short multidirectional dense chains. Precipitate thickness does not exceed 2-3 nm. The length, in many cases, is difficult to estimate, since precipitates in chains are often located close to each other and, therefore, merge. The rough estimate results are from $2-3 \mathrm{~nm}$ to 
10-12 nm. Thus, with a niobium content of at least $0.04 \mathrm{wt} . \%$ or with a vanadium content of at least $0.06 \mathrm{wt}$ \% in hot-rolled products, interphase precipitates may form and reduce its corrosion resistance. The study of such samples after heat treatment at $710{ }^{\circ} \mathrm{C}$ showed that the main structural changes in steel during heat treatment are the transformation of nanosized precipitates. After heat treatment, nanosized carbonitrides are located either in the form of short individual chains of precipitates formed in the ferrite (Figure 10a), or in the form of a set of parallel chains related to precipitates of the mixed type (Figure 10b). Precipitates of the mixed type nucleate and partially grow by the interphase mechanism, and then increase their volume in the ferrite region. The arrangement of such precipitates is the same as for interphase ones. The form of reflexes on the MDP may be various. Reflexes with tangential blurring (particles grew mainly by the interphase mechanism) and radial bands (particles grew mainly in the ferrite region) may be observed.

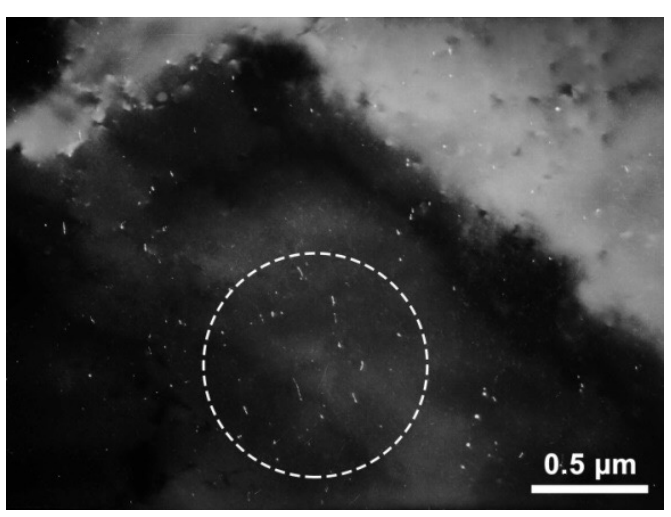

(a)

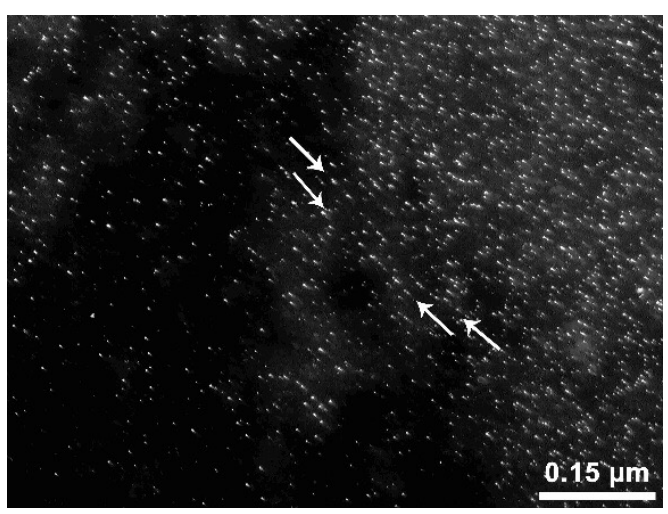

(b)

Figure 10. Dark-field image in reflections of nanosized carbonitrides (steel No 14): (a) Short individual chains of ferritic precipitates; (b) Parallel chains of precipitates of the mixed type.

As a result of the analysis of a large number of sample areas, it was found that precipitates of the mixed type predominate. The volume density of precipitates of the mixed type is high, the shape is moderately elongated, and the dimensions are $2-8 \mathrm{~nm}$ in length, up to $\sim 4-5 \mathrm{~nm}$ in the transverse direction. The volume density of the precipitates formed in the ferrite can be estimated as moderate. They are narrower, mainly up to 2-3 nm, while the scatter of sizes in length is very large: from the minimum observed $\sim 2 \mathrm{~nm}$ to $25-30 \mathrm{~nm}$ (see the areas marked with circles in Figure 10a). The structure of the matrix of the studied sample also contains precipitates formed in austenite, the size of which is $\sim 10-30 \mathrm{~nm}$. Thus, the main structural difference between heat-treated steel and hot-rolled steel is a large fraction of mixed and ferritic nanosized precipitates. At the same time, the fraction of interphase precipitates decreases. Obviously, this is due to the transformation of interphase precipitates into mixed-type particles during the heat treatment of rolled products in the ferrite region, as well as due to the formation of new precipitates of the ferrite type $[9,11,16]$. That is, the formation of an additional amount of ferritic nanosized precipitates is not a factor that has a negative effect on the corrosion resistance of steel. On the contrary, a decrease in the fraction of interphase precipitates, in this case, leads to an increase in the corrosion resistance. Thus, one of the new results obtained in this study is that mixed particles do not adversely affect corrosion resistance. In addition, the threshold values have been established for vanadium and niobium content, above which the formation of interphase precipitates and, accordingly, a decrease in the corrosion resistance of hot-rolled steels, is observed. One of the ways to increase the corrosion resistance of steels containing niobium and vanadium in concentrations above the threshold value is the use of heat treatment at a temperature of $710{ }^{\circ} \mathrm{C}$.

The results obtained also show that heat treatment of steels with the highest content of niobium $(0.05 \%)$ and vanadium $(0.08 \%)$ has a significant effect on the characteristics 
of precipitates of excess phases. After hot rolling, precipitates of the interphase type predominate in the steel. They are formed on planes corresponding to individual positions of the $\gamma \rightarrow \alpha$ transformation front. The arrangement of precipitates in electron microscopic images depends on the inclination of these planes relative to the foil plane: if it is close to perpendicularity, then long (sometimes in the full frame) approximately parallel chains of moderate density are observed; otherwise, the arrangement is chaotic. Reflexes in MDP usually show a slight tangential blur. In various areas, the sizes of interphase precipitates are slightly different. For example, in the section of the sample of steel No 17 (Figure 11a), the shape of the precipitates is approximately equiaxed, the size of the largest precipitates is not more than $2-3 \mathrm{~nm}$, and a portion is less than $2 \mathrm{~nm}$. In another area (Figure 11b) of the same sample, the precipitates are elongated, with a typical length of $2-4 \mathrm{~nm}$ (up to 5-6 $\mathrm{nm}$ ) and a width of up to 2-3 nm (the arrows indicate the most characteristic elongated particles). The volume density of such precipitates is high.

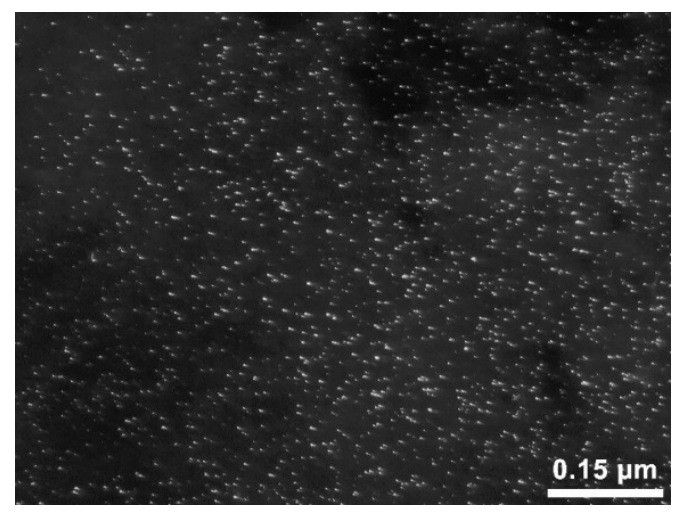

(a)

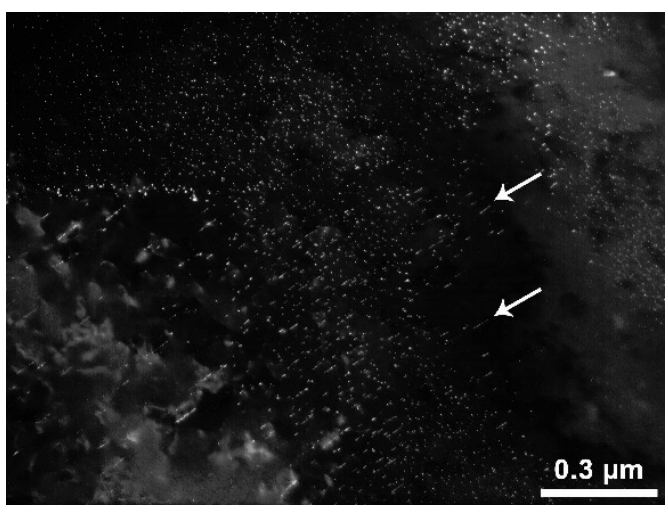

(b)

Figure 11. Dark-field image in reflections of nanosized carbonitrides (steel No 17): (a) Precipitates of approximately equiaxial shape with a size of no more than $2-3 \mathrm{~nm}$; (b) Elongated precipitates (the arrows indicate the most characteristic elongated particles).

After heat treatment, precipitates formed in austenite and ferrite, as well as mixed particles, prevail. The shape of austenitic precipitates changes from round to moderately elongated (sometimes there are particles closer to a square shape (some of them are indicated by arrows in the Figure 12a)): their sizes are $4-12 \mathrm{~nm}$ (up to about $20 \mathrm{~nm}$ ). Ferrite precipitates are very narrow (about $2 \mathrm{~nm}$ ), straight and elongated up to 60-70 nm (individual up to about $100 \mathrm{~nm}$ ) (circled in Figure 10b and indicated by arrows). The MDP clearly shows that the reflections related to precipitates have two components: 1 . Radially elongated bands; 2 . A component with tangential blur. In this area, apparently, there are both precipitates formed in ferrite and precipitates formed in austenite, and both have the same orientation. This assumption is confirmed by the fact that the precipitates have two directions of elongation (see Figure 12c): " 1 " (precipitates formed in ferrite) and "2" (formed in austenite). Mixed precipitates were also found (Figure 12d). Their volume density in this area is very high. The shape of the precipitates is elongated: the width is no more than $2 \mathrm{~nm}$, the length is $\sim 5-8 \mathrm{~nm}$ (up to 10-12 nm). The form of reflexes on MDP is in long narrow bands; hence, the bulk of the precipitate volume was formed in the ferrite region.

Thus, for these steels, as in the case of steels with a lower content of microalloying elements, the main structural difference between heat-treated steels and hot-rolled steels is a large fraction of nanosized mixed, ferritic and austenitic precipitates. A decrease in the fraction of interphase precipitates, in this case, leads to an increase in the corrosion resistance of steel. The positive effect of heat treatment at $710^{\circ} \mathrm{C}$ on the corrosion resistance of steel can also be associated with a decrease in the density of dislocations. This also confirms the fact noted above, that the mixed-type particles do not adversely affect the 
corrosion resistance of the steel. Thus, the use of heat treatment at $710^{\circ} \mathrm{C}$ makes it possible to obtain a saturation current density of no more than $6.22 \mathrm{~mA} / \mathrm{cm}^{2}$ even on steel with the highest vanadium and carbon content at a level of $0.08 \%$ each. As noted above, this corresponds to the corrosion rate in real operating conditions of oil field pipelines not exceeding $0.3 \mathrm{~mm} /$ year.

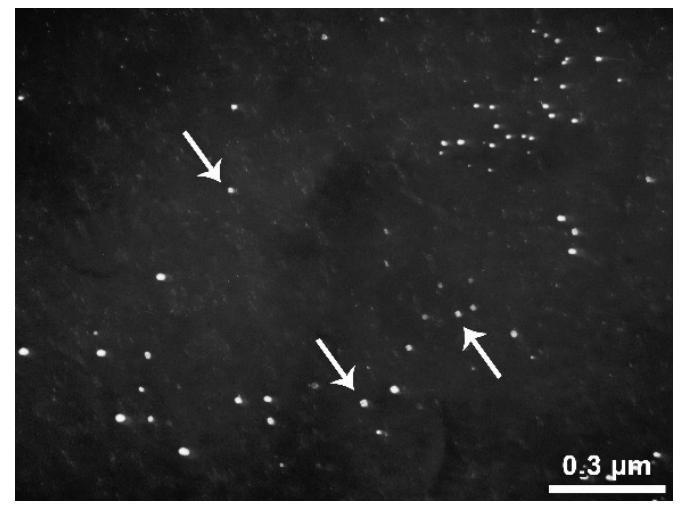

(a)

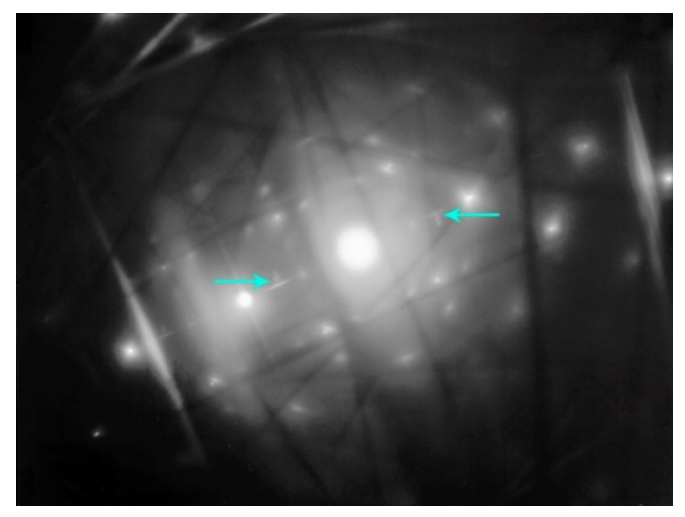

(c)

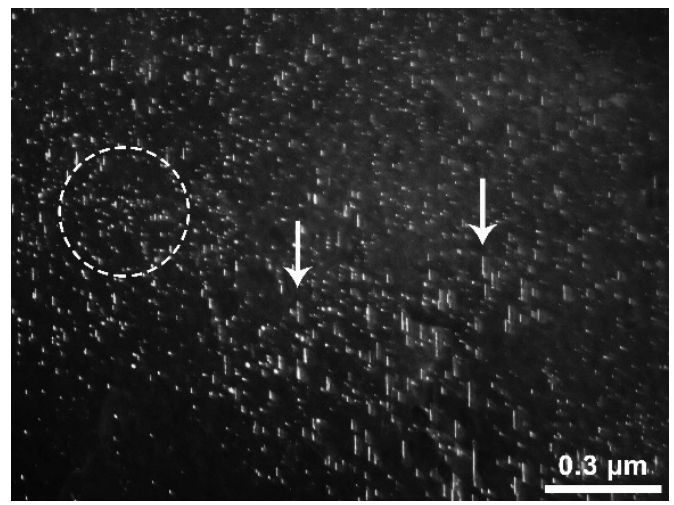

(b)

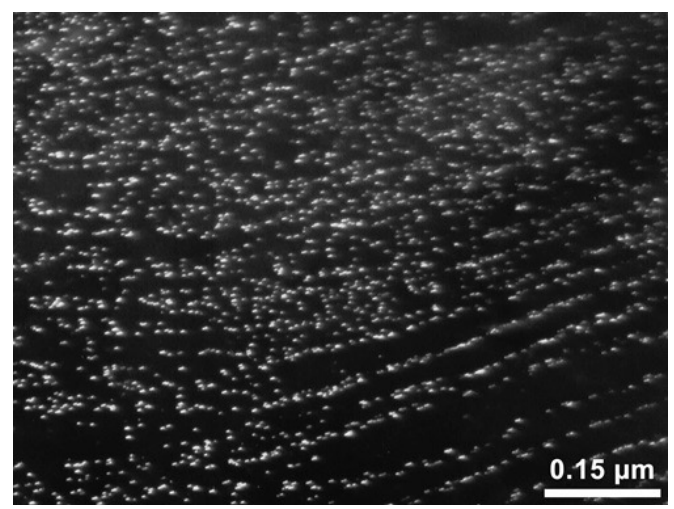

(d)

Figure 12. Dark-field image in reflections of nanosized carbonitrides (steel No17): (a) Austenitic precipitates (sometimes there are particles closer to a square shape (some of them are indicated by arrows); (b) Very narrow ferritic precipitates (about $2 \mathrm{~nm}$ ), straight and elongated in length up to 60-70 nm (individual up to about $100 \mathrm{~nm}$ ), circled in the figure and indicated by arrows; (c) Microdiffraction pattern (arrows indicate reflexes with two directions of elongation); (d) Precipitates of the mixed type.

\section{Conclusions}

The influence of the chemical composition and precipitations of carbonitride excess phases on the corrosion resistance of low-alloy steels in neutral aqueous environments, typical for the operating conditions of oil-field pipelines, has been investigated. It is shown that a decrease in the corrosion resistance of hot-rolled sheet products is caused by the presence of a large amount of nanosized precipitates of the interphase type, in particular, niobium carbonitride and vanadium carbonitride, the fraction of which increases with an increase in the content of carbon and microalloying elements (niobium and vanadium) above a certain level (content of niobium more than $0.04 \mathrm{wt} . \%$, vanadium more than $0.06 \mathrm{wt} . \%$ ). It was found that after heat treatment of such rolled products at $710{ }^{\circ} \mathrm{C}$, the corrosion resistance of the metal improves. One of the reasons for this is a decrease in the fraction of interphase precipitates, which have a negative effect on the corrosion resistance of steel, while precipitates formed in austenite and ferrite do not have such an effect.

Author Contributions: Conceptualization, I.R. and A.A.; methodology, E.A.; validation, I.R., A.A., E.A. and Y.G.; formal analysis, A.A.; investigation, I.R., A.A., E.A. and Y.G.; data curation, E.A., Y.G. 
and I.V.; writing—original draft preparation, E.A., Y.G. and I.V.; writing-review and editing, I.R. and A.A.; visualization, I.V.; supervision, I.R.; project administration, A.A.; funding acquisition, Y.G. All authors have read and agreed to the published version of the manuscript.

Funding: The reported study was funded by RFBR, project number 19-33-60094.

Institutional Review Board Statement: Not applicable.

Informed Consent Statement: Not applicable.

Data Availability Statement: The study did not report any data

Conflicts of Interest: The authors declare no conflict of interest.

\section{References}

1. Heidersbach, R. Metallurgy and Corrosion Control in Oil and Gas Production, 2nd ed.; Wiley: Hoboken, NJ, USA, 2018 ; p. 368.

2. Kane, R. Corrosion in petroleum production operations. In Metals Handbook, Volume 13C—Corrosion: Corrosion in Specific Industries; ASM International: Materials Park, OH, USA, 2006; pp. 922-966.

3. Ermakov, B.S.; Shaposhnikov, N.O. Effect of production factors on main oil pipeline pipe metal property formation. Metallurgist 2018, 62, 766-771. [CrossRef]

4. Amezhnov, A.V.; Rodionova, I.G. Effect of non-metallic inclusion chemical and phase composition on corrosion resistance of carbon and low alloy steels in water media typical for oilfield pipeline operating conditions. Metallurgist 2019, 63, 717-726. [CrossRef]

5. Kazakov, A.A.; Zhitenev, A.I. Assessment and interpretation of nonmetallic inclusions in steel. CIS Iron Steel Rev. 2018, 16, 33-38. [CrossRef]

6. Kazakov, A.; Zhitenev, A.; Ryaboshuk, S. Interpretation and classification of nonmetallic inclusions. Mater. Perform. Charact. 2016, 5, 535-543. [CrossRef]

7. Amezhnov, A.V.; Rodionova, I.G.; Mogutnov, B.M. Establishment of optimum production regimes for extra-furnace processing of low-alloy steels in order to ensure their good corrosion resistance in aqueous media through formation of favorable non-metallic inclusions. Refract. Ind. Ceram. 2020, 60, 521-526. [CrossRef]

8. Khalaj, G.; Khalaj, M.J. Investigating the corrosion of the Heat-Affected Zones (HAZs) of API-X70 pipeline steels in aerated carbonate solution by electrochemical methods. Int. J. Press. Vessel. Pip 2016, 145, 1-12. [CrossRef]

9. Rodionova, I.G.; Feoktistova, M.V.; Baklanova, O.N.; Amezhnov, A.V.; D'yakonov, D.L. Effect of chemical composition and microstructure parameters on carbon and low-alloy steels corrosion resistance. Metallurgist 2018, 61, 770-776. [CrossRef]

10. Amezhnov, A.V.; Rodionova, I.G.; D'yakonov, D.L.; Dunaev, S.F.; Gladchenkova, Y.S. Effect of chemical composition and parameters of microstructure on corrosion resistance of high-strength rolled products from low-alloy steels in aqueous environments. Met. Sci. Heat Treat. 2021, 62, 640-647. [CrossRef]

11. Amezhnov, A.V.; Rodionova, I.G.; Batsalev, A.I.; D'yakonov, D.L.; Shaposhnikov, N.G.; Shatskii, T.E.; Marzoeva, M.E. Effect of chemical composition and microstructure parameters on carbon and low-alloy steel corrosion resistance under oil industry pipeline operation conditions. Metallurgist 2019, 62, 1030-1038. [CrossRef]

12. Scholz, F. Electroanalytical Methods: Guide to Experiments and Applications; Springer: Berlin/Heidelberg, Germany, 2010 ; p. 328. [CrossRef]

13. Narimani, N.; Zarei, B.; Pouraliakbar, H.; Khalaj, G. Predictions of corrosion current density and potential by using chemical composition and corrosion cell characteristics in microalloyed pipeline steels. J. Int. Meas. Conf. 2014, 62, 97-107. [CrossRef]

14. Nenasheva, T.A.; Marshakov, A.I.; Ignatenko, V.E. The influence of alternating current on stress corrosion cracking of grade X70 pipe steel. Prot. Met. Phys. Chem. Surf. 2020, 56, 1223-1231. [CrossRef]

15. Rodionova, I.G.; Zaitsev, A.I.; Baklanova, O.N.; Kazankov, A.Y.; Endel, N.I.; Kudashov, D.V.; Semernin, G.V.; Tsibrov, S.E. A Method for Assessing the Corrosion Resistance of Carbon and Low-Alloy Pipe Steels and Pipes Made from Them. Patent RU 2554659, 15 June 2015.

16. Candra, T.; Torralba, J.M.; Sakai, T.A. Quantitative Study of Interphase Precipitation in a Commercial Microalloyed Steel. Mater. Sci. Forum 2003, 426-432, 1517-1522. [CrossRef]

17. Karjalainen, L.P.; Porter, D.A.; Järvenpää, S.A. Atomic Scale Investigation of Solutes and Precipitates in High Strength Steels. Mater. Sci. Forum 2013, 762, 14-21. [CrossRef]

18. Bréchet, Y.; Clouet, E.; Deschamps, A.; Finel, A.; Soisson, F. Influence of Alloying Elements on Precipitation Behavior of VCN in Middle Carbon Steels. Solid State Phenom. 2011, 172-174, 408-413. [CrossRef]

19. Rodionova, I.G.; Amezhnov, A.V.; Kudashov, D.V.; Naumenko, V.V.; D’yakonov, D.L.; Stukalova, N.A.; Arutyunyan, N.A. Effect of heat treatment in pipe processing stage on corrosion resistance of micro-alloyed steel hot-rolled products. Metallurgist 2020, 64, 322-333. [CrossRef]

20. Lin, L.; Li, B.S.; Zhu, G.M.; Kang, Y.L.; Liu, R.D. Effect of niobium precipitation on microstructure and hydrogen induced cracking of press hardening steel 22MnB5. Mater. Sci. Eng. A 2018, 721, 38-46. [CrossRef] 
21. Kim, H.J.; Jeon, S.H.; Yang, W.S.; Yoo, B.G.; Chung, Y.D.; Ha, H.Y.; Chung, H.Y. Effects of titanium content on hydrogen embrittlement susceptibility of hot-stamped boron steels. J. Alloy. Compd. 2018, 735, 2067-2080. [CrossRef]

22. Zhang, S.; Huang, Y.; Sun, B.; Liao, Q.; Lu, H.; Jian, B.; Mohrbacher, H.; Zhang, W.; Guo, A.; Zhang, Y. Effect of Nb on hydrogen-induced delayed fracture in high strength hot stamping steels. Mater. Sci. Eng. A 2015, 626, 136-143. [CrossRef]

23. Chen, W.; Gao, P.; Wang, S.; Lu, H.; Zhao, Z. Effect of vanadium on hydrogen embrittlement susceptibility of high-strength hot-stamped steel. Iron Steel Rees Int. 2020, 28, 211-222. [CrossRef]

24. Huang, W. Suppression of hydrogen-induced damage in 22MnB5 hot stamping steel by microalloying. Mater. Chem. Phys. 2020, 256, 123-129. [CrossRef]

25. Opiela, M.; Ozgowicz, W. Effects of Nb, Ti and V on recrystallization kinetics of austenite in microalloyed steels. J. Achiev. Mater. Manuf. Eng. 2012, 55, 759-771.

26. Ozgowicz, W.; Opiela, M.; Grajcar, A.; Kalinowska-Ozgowicz, E.; Krukiewicz, W. Metallurgical products of microalloy constructional steels. J. Achiev. Mater. Manuf. Eng. 2011, 44,7-34.

27. Fernandez, A.I.; Uranga, P.; Lopez, B.; Rodrigues-Ibabe, J.M. Dynamic recrystallization behavior covering a wide austenite grain size range in $\mathrm{Nb}$ and $\mathrm{Nb}$-Ti microalloyed steels. Mater. Sci. Eng. 2003, A 361, 367-376. [CrossRef]

28. Benscoter, A.O.; Perricone, M.J. Marshall's Reagent: Origins, Modifications, and New Applications. Microsc. Microanal. 2005, 11, 76-77. [CrossRef]

29. Opiela, M. Analysis of the kinetics of precipitation of MX-type interstitial phases in microalloyed steels. J. Achiev. Mater. Manuf. Eng. 2011, 47, 7-18. 